\title{
REQUERIMIENTO Y FALLO SOBRE INCONSTITUCIONALIDAD DEDUCIDO EN CONTRA DE ALGUNAS DISPOSICIONES DE LAS "NORMAS NACIONALES SOBRE REGULACIÓN DE LA FERTILIDAD", APROBADAS POR EL DECRETO SUPREMO No 48, DE 2007, DEL MINISTERIO DE SALUD
}

Nota del Editor: El texto completo del requerimiento, del Decreto Supremo № 48 y de las Normas Nacionales sobre la Regulación de la Fertilidad, respectivamente se hallan en: http://www.tribunalconstitucional.cl/index.php/sentencias/download/pdf/914), http://www.minsal.cl/juridico/DECRETO_48_07.doc, http://www.flacso.cl/flacso/biblos.php?code=2331 TIVA":

1. "SECCIÓN C: TECNOLOGÍA ANTICONCEP-

a) PUNTO 3.3. "ANTICONCEPCIÓN HORMONAL DE EMERGENCIA", y b) PÁRRAFO 4 "ANTICONCEPCIÓN NO HORMONAL", PUNTO 4.1.1. "DISPOSITIVOS INTRAUTERINOS".

Dichas normas se impugnan, conforme señalan los peticionarios, sólo en cuanto autorizan la distribución y el uso de la denominada "Píldora del Día Después", ya sea a través de la entrega de una sola pastilla de progestina pura, generalmente levonorgestrel al 0,75 mg., o a través de la combinación de píldoras, método denominado "Yuzpe", y "la utilización del dispositivo intrauterino (DIU)". "Éste corresponde a uno (sic) de las posibilidades de la llamada anticoncepción con progestágeno solo". Afirman los requirentes que el mecanismo de acción de los métodos individualizados sería idéntico, en cuanto a que producen una alteración endometrial que actúa impidiendo la anidación del individuo ya concebido y, desde tal perspectiva, indican, serían contrarios a lo preceptuado en los artículos 5, inciso segundo, $6^{\circ}, 7^{\circ}$ y 19 , №s. 1 y 26 , de la Carta Fundamental.

2. "SECCIÓN D: ANTICONCEPCIÓN EN POBLACIÓN ESPECÍFICA".

La declaración de inconstitucionalidad de estas normas se pide en cuanto regulan "la conse- jería a adolescentes que se da en el marco de la confidencialidad, esto es, sin el consentimiento ni conocimiento de los padres", lo cual, a juicio de los peticionarios, sería contrario a lo dispuesto en el inciso tercero del № 10 del artículo 19 de la Carta Fundamental.

3. Se pide entender también impugnado el PUNTO 1.

"ANTICONCEPCIÓN PARA ADOLESCENTES", de la referida SECCIÓN D.

La acción de inconstitucionalidad se dirige en este punto a dos aspectos, según se indica por los requirentes:

a) en cuanto admite la administración de la anticoncepción de emergencia bajo la modalidad de la "Píldora del Día Después como pastilla única y combinada", lo cual resultaría contrario a los preceptos constitucionales invocados al referirse a las primeras disposiciones reglamentarias impugnadas en la especie, y

b) por cuanto, la consejería confidencial que se otorga a los adolescentes vulnera el derecho y deber preferente de los padres a educar a sus hijos, reconocido en la norma constitucional citada en el numeral 2 precedente.

\section{SE RESUELVE:}

1. Que se acoge el requerimiento únicamente en 
cuanto se declara que la Sección C., acápite 3.3, "Anticoncepción Hormonal de Emergencia", así como la Sección D., "Anticoncepción en Poblaciones Específicas", acápite 1, sólo en la parte que se refiere a la "anticoncepción de emergencia", de las Normas Nacionales sobre Regulación de la Fertilidad, que forman parte del Decreto Supremo № 48, de 2007, del Ministerio de Salud, son inconstitucionales.

2. Que, en consecuencia, se desestima el requerimiento, en cuanto impugnó la Sección C, acápite 4, "Anticoncepción No Hormonal", punto 4.1.1. "Dispositivos Intrauterinos", de las Normas $\mathrm{Na}$ cionales sobre Regulación de la Fertilidad, que integran el Decreto Supremo № 48, de 2007, del Ministerio de Salud.

3. Que asimismo se rechaza el requerimiento, en cuanto impugnó la consejería a adolescentes en el marco de confidencialidad sin conocimiento ni consentimiento de los padres, contenida en la Sección D., bajo el título "Anticoncepción en Poblaciones Específicas", acápite 1, "anticoncepción en adolescentes", de las Normas Nacionales sobre Regulación de la Fertilidad, contenidas en el Decreto Supremo № 48, de 2007, del Ministerio de Salud, sin perjuicio de lo resuelto en el № 1 . 